Please do not remove this page

RMIT

UNIVERSITY

\title{
What's in a WordTM? When one electronic document format standard is not enough
}

Magee, Liam; Thom, James

https://researchrepository.rmit.edu.au/esploro/outputs/9921862168401341/filesAndLinks?institution=61RMIT_INST\&index=null

Magee, L., \& Thom, J. (2014). What's in a WordTM? When one electronic document format standard is not enough. Information Technology and People, 27(4), 482-511. https://doi.org/10.1108/ITP-09-2012-0096

Document Version: Accepted Manuscript

Published Version: https://doi.org/10.1108/ITP-09-2012-0096

Repository homepage: https://researchrepository.rmit.edu.au

(C) 2014 Emerald Group Publishing Limited

Downloaded On 2023/04/26 15:03:46 +1000

Please do not remove this page 
Thank you for downloading this document from the RMIT Research Repository.

The RMIT Research Repository is an open access database showcasing the research outputs of RMIT University researchers.

RMIT Research Repository: http://researchbank.rmit.edu.au/

\section{Citation:}

Magee, L and Thom, J 2014, 'What's in a WordTM? When one electronic document format standard is not enough', Information Technology and People, vol. 27, no. 4, pp. 482-511.

See this record in the RMIT Research Repository at:

https://researchbank.rmit.edu.au/view/rmit:29076

Version: Accepted Manuscript

Copyright Statement: @ $c 2014$ Emerald Group Publishing Limited

Link to Published Version:

http://dx.doi.org/10.1108/ITP-09-2012-0096 


\section{Introduction}

"Standards efforts lead to standards, but not always the ones that were intended” (Sowa, 2004).

Standards setting is a complex process, involving many actors, activities and technical artefacts (Ganesh, 2010). As Sowa's oft-cited law of standards suggests, efforts to set standards often produce unintended consequences: standards that do not reflect the interests of their authors, nor the interests of a broader public they are designed to serve (Cargill, 2011). Conversely, the development of particular standards can sometimes kick back upon mechanisms for standardisation themselves. International standards setting has often been perceived as a sober and obscure activity, conducted behind closed doors by technical committees, comprising experts who represent a select institutional group of technology corporations and government offices (Morris, 2011). Increasingly, however, the setting of standards has attracted public scrutiny, particularly in the online sphere, and especially where the standard in question has evident economic and political stakes. Hence the success of standards can now be seen as at least partially dependent upon the ability of the standardisation process to appear open and creditable to a broader audience (David \& Shurmer, 1996).

The case of the standardisation of two ISO electronic document formats, the OpenDocument Format (ODF) and Office Open XML (OOXML), aptly fulfils Sowa's dictum. Initial efforts to create a single open document standard eventuated in the emergence of two standards, largely overlapping and only partially compatible (Blind, 2011; Egyedi \& Koppenhol, 2010). The case highlights two further, and contradictory, aspects of modern IT standards development. The first of these is that, as van Wegberg (2004) and Egyedi \& Koppenhol (2010) suggest, corporate and consortia-based standards development can lead to technological fragmentation, higher market entry costs and end-user confusion. In this case, the attempt to design a de jure standard in fact produced even greater entrenchment of the existing de facto standard it was designed to replace. The second aspect is that the process of setting standards is now a publicly discursive affair, with standards sponsors, opponents, the media and general public increasingly engaged in debate through online social media. As exemplified by this debate, what Fairclough (1993) has described as the "conversationalisation" of institutional public discourse can, we argue, act as a countermeasure to the corrosive effects of the corporatisation of standards, and ultimately offer potential for more participatory standards processes. This particular case shows that critical public discourse, while not necessarily conducive to consensus building, can foster a degree of change in the ways standards are created and used by institutions. This change is evident in two ways in the years since. First, standards bodies like ISO are using social media channels such as Facebook, Twitter, Google Hangouts and YouTube to engage the public in conversation about existing and emerging standards (ISO, 2013). Second, new models for standards development are emerging from the open source software community, supported by social code sharing systems such as GitHub and Bitbucket. Standards developed in this way frequently follow institution-like protocols, with standards recommendations, membership and voting systems, but can be freely debated, forked and adapted into different "flavours" by any technically proficient member of the public (PHP Framework Interoperability Group, 2013; GitHub, 2013).

In our case study, the incumbent and de facto standard is represented by the Microsoft Office document format, standardised in practice by the near-monopolistic dominance of Microsoft in the office suite market. The role of the pretender de jure standard is played by ODF, a format proposed by a consortia of rival companies and ratified by the International Organization for Standards (ISO) in 2006 (ISO/IEC, 2006). Microsoft responded with a de jure standardisation effort based on its own proprietary format immediately, and, after a protracted struggle, its alternative, OOXML, was also ratified by ISO (ISO, 2008a). The period covering the standardisation of both formats, 2005 to 2008, elicited considerable commentary, much of it available via online social media, blogs and mailing lists. As the authors of the Burton Group's report on the two competing formats colourfully describe:

The software industry has rarely seen debates as intense ... It's a story that has many elements appropriate for a James Bond movie, with multibillion dollar business empires at risk, global political intrigue, and even some conspiracy theories at the interaction of capitalism (commercial software products), democracy (industry standards), and communism (e.g., related standards controlled by the People's Republic of China). This is improbably heady stuff for what's ultimately a debate about something as mundane as file formats. (O’Kelly \& Creese, 2008) 
The proliferation of such "heady stuff”, however improbable, nonetheless announces the increasing role of the public as an active player in standards development. The economic and political stakes of IT standards have never been higher. In the six month period leading up to the final decision to ratify OOXML, Microsoft's Business Division reported \$8.9 billion USD in revenue and \$5.8 billion USD in operating income, $90 \%$ of which are made up by Microsoft Office sales (Microsoft Corporation, 2008b). Such figures translate into tremendous political influence over the IT policy and governance bodies that vote on international standards, even in the presence of similarly powerful corporate rivals. Equally evident is the influence corporate interests can exert, to promote private proprietary standards as public goods through media channels. This case of standardisation is remarkable for the degree to which both advocates and opponents of OOXML took to online social media to prosecute their causes. It therefore offers opportunity to examine how a discourse about standards can be constructed for public consumption by institutional actors; and how, in turn, non-institutional actors respond, often critically, to the perceived abrogation of public goods that standards supply. The ratification of OOXML offers evidence of two contradictory features, then, of standardisation: on the one hand, the corporatisation of standards processes; and on the other, the deflationary potential of the public discursive sphere, especially evident in online social media, on those processes.

We argue here that this counterweight influence of social media can serve to vitiate the worst excesses of institutional actors sponsoring and steering standards towards their own interests. We first discuss recent literature on standards and openness, and introduce the theoretical lens, discursive institutionalism, through which we study the controversy. We then present a narratological account of the standardisation of OOXML, interwoven with analysis of the discursive operations employed by the various actors involved in this standardisation process. We conclude with remarks about specific role of social media in this case, and implications for future software standards development.

\section{Openness of Standards}

Information technology standards are frequently interpreted as unadulterated public goods, promoting lower costs (Jain, 2012), reducing information asymmetry between producers and consumers (Clarkson et al., 2007), fostering innovation (Grøtnes 2009), improving quality (Siponen \& Willison, 2009) and enabling interoperability between technology artefacts (Egyedi \& Blind, 2008). As Dolmans (2010) has suggested, standards can be understood as alleviating mechanisms for the "tragedy of the anti-commons", where copyright and patents serve to limit competition and diffusion of public goods. By introducing compatibility between rival vendor products, standards can instead foster positive network externalities, increasing the size and value of the market and benefitting all vendors simultaneously (Katz \& Shapiro, 1985). Portugal-Perez et al. (2010) note that standards also provide an informational effect, indicating customer preferences to vendors - a valuable asset, even though this comes with the additional cost of standards-compliance. Standards also function at a high level of signalling, identifying particular spatial-temporal objects as commoditised products and services to the market (Thevenot, 2009).

There is considerable variation in the nature and function of IT standards. For instance, Egyedi \& Blind (2008) distinguish committee standards from de facto standards. They further differentiate committee institutional types between formal standards organisations, and less formal standards consortia and professional organisations. These institutions play different roles in the development of standards. While standards consortia frequently play an incubating role in the development of standards, standards development organisations facilitate the negotiation, voting and ratification of standards across a larger international forum (Weiss and Cargill, 1992; Van Wegberg, 2004). Conversely, de facto standards evolve through the "unco-ordinated initiatives of large numbers of actors" (Vrancken et al., 2008), reflecting in such cases largely benevolent "bottom-up" and creative processes. However de facto standards can also emerge from what only appears a lack of co-ordination, when a single or small number of vendors come to dominate a market, and so standardise a particular product offering. As Ghosh (2011) notes, in this event a monopoly can take advantage of the network effects of a standard when it controls both its provision and price. Recognition of this rent-seeking practice by governments, consumers and rival vendors can in turn lead to the promotion of de jure standards that seek to re-externalise the value that had been internalised through inflated pricing. Such efforts share similarities with anticipatory standards, used to create de facto practice from de jure fiat, helping shape the form of the market itself (Grøtnes, 2009). A key difference in the case of monopolistic control is that a large existing base of consumers may be resistant to the introduction of a novel de jure standard, particularly if it is incompatible with an entrenched de facto standard. As Murphree \& Breznitz (2011) and Egyedi \& Koppenhol (2010) note, this can lead to a counter-productive situation: 
multiple standards that confuse rather than enlighten consumers, and stifle rather than encourage innovation and competition. In extreme cases, the de facto vendor can also wield disproportionate influence over the purportedly neutral procedural mechanisms used to ratify standards.

A possible remedy has been sought in the idea of open standards (Krechmer, 2006; Dolmans, 2010). Open standards limit the possibility of corporate rent-seeking over standards (whether de jure or de facto), as costs and other barriers to competition are lowered (Ghosh, 2011). Definitions of "openness" remains highly contested, however, both in the literature and in the broader community of standards developers and users. The ITU-T (International Telecommunications Union) offered an early definition:

"Open Standards” are standards made available to the general public and are developed (or approved) and maintained via a collaborative and consensus driven process [our emphasis]. "Open Standards" facilitate interoperability and data exchange among different products or services and are intended for widespread adoption (ITU, 2005).

The European Commission's definition includes a similar focus on process, discussing the roles of a "nonfor-profit" standard custodian and "open decision-making procedure" (European Commission, 2004). In other frequently cited definitions, Perens (2006) stipulates 6 principles that include availability, choice, extensibility, avoidance of royalty, discrimination and predatory practices, while Krechmer (2011) lists ten requirements that include ensuring inclusivity of stakeholders, due process, negligible IP restrictions, availability of relevant documents and software interfaces, and ongoing support. While these definitions vary in their respective emphases, they share a common element of procedural openness. Variously termed absence of "discrimination", "inclusivity of stakeholders", "open decision-making” or "collaborative and consensus driven process", this element emphases that the way standards are developed - as much as their end products - remain open to diverse groups of competing vendors, customers and the broader public. The absence of procedural openness allows for the development of superficially open standards that nevertheless play to specific corporate interests.

In the document formats case discussed here, the question of openness has particular valence. Firstly, both standards include the term "open" in their names, as kinds of brands or signatures of their intent. Yet as Shah \& Kesan (2008) note, this rhetorical gesture itself provided guarantee neither of interoperability between the formats, nor of greater accessibility to end-users. In other studies of the case, "openness" has been used in three distinct ways: in the procedural sense we allude to above, concerning the openness or inclusivity of stakeholders in the standardisation process (Rens, 2011); in the economic sense of markets being opened up by standards to increased competition (Blind, 2011); and in the political sense of open engagement between vendors, governments, and citizens (Egyedi \& Koppenhol, 2010). In discussing the feedback process for OOXML comments from ISO members, Rens (2011) argues that emerging economies like South Africa, Brazil and India continue to be marginalised in ISO discussions, and that open standards - in the sense of standards that have broader forms of input into their development - provide a potential remedy. Discussing the economic impact of OOXML ratification, Blind (2011) argues that the uncertainty of "future user preferences" for document formats means that rival formal (e.g. ISO-ratified) standards should be given opportunity to be contested by market mechanisms. This would lead both to the improved technical quality of both standards, and to some degree of harmonisation between them, with the end result being a more economically efficient outcome. Egyedi \& Koppenhol (2010) argue, contra Blind, that such competition, in the case of de jure standards, limits rather than promotes such innovation, doubling up costs of standards maintenance, conformance testing and document conversion. A far-reaching societal consequence is the closing-off - rather than the opening-up - of "supplier-independent information exchange between government and citizens” (Egyedi \& Koppenhol, 2010).

Building upon the hints offered by Egyedi and Koppenhol, here we argue for another, specifically discursive, sense of openness that is at stake in standards development. Indirectly contributing to the sense of procedural openness, we suggest that the very proliferation of public discursive commentary and critique in the OOXML standardisation case - on behalf of corporate institutions engaged in formal standards processes, but also including both governments and citizens - draws attention to and challenges the power and control institutions exert over processes of standardisation. In spite of whatever intent and interests might be ascribed to Microsoft and its corporate rivals, the use of social media in this case can be seen to be offering ambiguous potentials for greater participation and openness in the standards setting arena. 


\section{Discursive Institutionalism and the Construction of Standards}

Recent decades have witnessed a renewed flourishing of studies of institutional structures, frequently under the rubric of new institutionalism. Though now encompassing a broad range of disciplines and approaches (Hall \& Taylor, 1996; Schmidt, 2008), new institutionalism generally seeks to emphasize the situatedness of institutions - with respect both to society as a whole, and to individual actors. In a seminal early example, DiMaggio \& Powell (1983) examined the institution as a quasi-organic entity. Subsequent studies have described the embeddedness of institutions in broader social networks, practices and informal interpersonal ties (Granovetter, 1985; Nee, 2003); the narratives that underpin specific institutional discourses (Czarniawska-Joerges 1995; Czarniawska and Mazza, 2013); and the informal norms that shape institutional behaviour over time (North, 1994). While institutions continue to be conceived broadly along Weberian lines - marked by rule-compliance and regulation - new institutionalism envisages a more complex set of relationships between institutions and the social context they inhabit. Rather than unshakeable "iron cages", institutions have increasingly been seen as quasi-organic, porous, adaptive, capable of learning and memory, and subject to a range of external forces and pressures (DiMaggio \& Powell, 1983; Granovetter, 1985; North, 1994). One such emergent force is information technology, which has played a transformative role in the evolution of the modern institution (Fountain, 2001). A role further radicalised recently through the proliferation and ubiquity of social media (Mergel et al., 2009; Fountain, 2011), serving to create stronger and potentially disruptive - discursive ties between institutions and other social actors.

From another perspective, the ways in which information technology and social media affect institutional arrangements have been developed in a recent variant of new institutionalism termed discursive institutionalism (Schmidt, 2008). In contrast to other forms of new institutionalism, discursive institutionalism aims to better account for the way in which language and discourse mediate power relations between an institution and other - social, institutional or individual - actors. While studies of organisational and governmental uses of language are not novel (Latour and Woolgar, 1979; Foucault, 1980; Flybgjerg, 1998), the epistemological emphasis here is on the hinge between (institutional) structure and (individual) agency. Within the discursive institutional frame, institutions continue to play a structuring role in terms of the ideas and actions of social agents; at the same time, institutions themselves are no longer impervious to the dynamic role played by those agents. For Schmidt (2008), discourse is the critical intermediary that both allows institutions to establish the "background ideational abilities" of actors, and for actors to exercise "foreground discursive abilities" that account for institutional change.

Discursive institutionalism provides a fitting frame for understanding the processes of IT standards setting. Standards can be seen archetypal discursive formations for the production of what DiMaggio \& Powell (1983) have termed "institutional isomorphism”, where growing institutions gradually develop similar characteristics over time. Standards accelerate such conformity; and information standards, particularly, operate explicitly as inter-institutional normative discourses, setting expectations between institutional actors for how informational resources should be transacted (Timmermans \& Epstein, 2010). According to ISO (2013), "a standard is a document that provides requirements, specifications, guidelines or characteristics that can be used consistently [our emphasis] to ensure that materials, products, processes and services are fit for their purpose”. Both the means and the ends of standards development involve inherently discursive practices: creating a committee-based standard, in particular, requires instrumentation through consultative processes and agreements, documented in agendas, minutes, and the resultant draft and final specifications that grant the standard an institutional imprimatur. Rather than being a mere medium for communication, institutions use discourse performatively in standards-setting environments: to set agendas, to establish influence, to establish behavioural norms within and beyond institutional boundaries. As Flyvgjerg (1997) notes in another institutional context, rationality and power are invariably intertwined through these kinds of acts and interventions, in spite of the overtly rational goal of standards development.

Social media is increasingly becoming a new ideal type of institutional discourse - albeit one with ambiguous potentials for institutional change (Fountain, 2009, 2011). In the context of standards setting, social media obscures the traditional divisions between insider experts, typically representing corporate institutions, and outsider users of standards. The current case study of the document controversy showcases how discourse, particularly when enacted through online public avenues, reflects this complex and dynamic interplay. This complicates, on the one hand, official narratives of steady-state information technology standards development, in which rational technical experts arrive at consensus through idealized communicative action. On the other hand, it similarly complicates critical narratives that imagine institutions blindly following structural mandates - "rules of the game" - without a role for individual agency to provide critical feedback. Our study here argues that standards processes have features of both institutional 
determination and individual agency, and that the growth of online social media offers something of an ambiguous opening for non-institutional dissent to be voiced through.

\section{Methodology}

As we discuss above, the case of OOXML standardization represents a significant turning point in the discursive forms deployed in high-profile standards development. In this context, and following more general definitions by van Dijk (1993) and Fairclough (1993), discourse refers to the specific use of language to articulate, construct, negotiate and determine positions that align a standard to institutional interests. Discourse about standards can include the use of key rhetorical terms, such as "openness", "standards", "interoperability" and "harmonization", as well as strategic uses of language to shift the frame of debate, to highlight or silence given points of view, to broaden or narrow the scope of discussion, and to incorporate or align other interests with one's own. A common rhetorical manoeuvre, for example, is to deflect the interests inherent in promoting a given standard onto the "customer" - a diffuse stakeholder that cannot be readily seen or held to account. Both advocates and opponents employed this tactic, to construct an idealized actor whose interests are best served by either the ratification, or the failure to ratify, OOXML as the standard. Hence, as Foucault (1980), van Dijk (1993), Fairclough (1993) and others have argued, discourse can incorporate a range of both explicit speech acts and implicit rhetorical framing devices to serve particular interests. As Hacking (2011) notes, in an institutional context discourse analysis has strong resonance with Goffman's early dramaturgical accounts of self-presentation and interaction, where individuals perform roles strategically aware of and informed by the context and each other. This case fortuitously offers a rich vein of publicly available textual sources that demonstrate how institutional strategies are deployed through discourse.

Schmidt does not explicitly outline a methodological program to accompany her theoretical case for discursive institutionalism. However recent discursive institutionalist research has tended to rely upon case studies rich in discourse and textual analysis (Amaeshi, 2011; Lauber \& Schenner, 2011; Fairbrass, 2011). Arts \& Buizer (2009) see discourse as inhabiting a spectrum from narrow "discourse as text” through to broad "discourse as social practice". Applied studies in discursive institutionalism have accordingly interpreted discourse in line with this narrow-to-broad spectrum: in some cases analyzing a selective corpus of documents (Amaeshi, 2011), in others examining the use of rhetorical and discursive frames across a broader body of literature (Arts \& Buizer, 2009).

This case study adopts something of a middle ground methodologically, utilizing a range of publicly available textual sources to develop a dramaturgical narrative and analysis of the institutional and individual actors at work. The majority of documentary evidence used to compile the narrative was authored during the period of the controversy, 2005 - 2008, and reflects perspectives of key institutional sponsors of both ODF and OOXML document standards, members of the ISO standards committee, government officials, and various commentators and consultants. The genres of discourse span technical specifications of the standards through to political commentary expressed in blog posts, online forums and wiki comments. Sources were selected through a combination of Internet searches and cross-references, and included conversational documentary sources published through blogs, wikis and social media, as well as documents designed for specific audiences, including meeting minutes, press releases, technical reports and specifications, and SEC filings. Authors included employees of Microsoft and of rival technology companies (principally IBM and Sun Microsystems), as well as other commentators who sought to influence ISO members in the lead-up to the ratification vote in 2008. We selected documents that reflect the following discursive distinctions:

- Published formally / informally

- Authors affiliated institutionally / authors (at least seemingly) unaffiliated

- Intended for public consumption / intended for specific (technical, financial) audiences

- For, against, or neutral with respect to the ISO ratification of OOXML

Sources were then grouped by organization and discourse type, as listed below in Table 1 .

\section{[Insert Table 1 here]}

We present the analysis in the form of a chronological narrative informed by these sources, and intersperse analysis of key metaphors and rhetorical moves deployed by those sources to shore up particular ideological 
positions within the debate. As our narrative below shows, social media has become a means for onceprivate discussions to be played in the public sphere by institutional actors. It also allows other, noninstitutional actors to enter the discursive fray; as our list of sources show, a number of independent bloggers and commentators sought to engage with the standardization process by way of direct commentary and responses, as well as through hypertext links and summaries. In this narrative the main stage is clearly occupied by institutional protagonists - by Microsoft and its corporate rivals, and to a lesser degree, by standards bodies such as Ecma International and ISO - and the controversy plays out as a sequence of discursive acts performed by these actors. Bloggers and commentators appear at first instance as the part of the global audience of customers of document formats and systems. However the boundary between actor and audience becomes somewhat blurred as the drama unfolds, and those on the stage begin to use lines articulated by vocal by-standers. While social media has a modest transformative effect on this particular drama, and indeed on the institutions involved, its use points the way towards a more potentially radical "flattening" of the stage upon which standards are developed.

\section{A Tale of Two Formats}

\section{The Challenge of the ODF}

One point of origin for the document format controversy is the obscure acquisition of Star Office, a littleknown German software company which developed a software office suite of the same name, by Sun Microsystems in 1999 (Shankland, 1999). Sun supposedly rationalised the acquisition of the company, for \$73.5 million USD, as being a cheaper way of providing office software for its own employees than purchasing Microsoft Office licenses (Lai, 2007). Soon after it released the source code to the software under the name of OpenOffice, with an accompanying open source license. Although it continued to sell Star Office, along with documentation and support, the act of releasing the source code was an important public relations gesture, and the community that then developed around the open source version was to become an important activist group. The rising use of OpenOffice, though still insignificant compared to Microsoft Office, soon propelled an effort to standardise its XML-based file format, known as the OpenDocument Format (ODF).

The development of ODF was largely motivated by and funded by a consortium of IT companies, all in some way rivals of Microsoft. Though ostensibly pitched towards benefits of a social and political nature - lower software costs, enhanced interoperability and greater transparency - ODF was clearly also intended to disrupt Microsoft's seemingly impenetrable hegemony of operating system and office suite markets. Early proponents of ODF, Sun Microsystems, Novell Corporation and IBM, were later enthusiastically joined by other competitors, Google and Oracle, and an increasingly active and vocal open source community. Given the costs associated with its development, such a document format is unlikely to have been developed were it not for the timely confluence of this corporate and open source alignment with wide governmental dissatisfaction with the near-monopolistic dominance of Microsoft. To encourage industry participation in the development of ODF, Sun Microsystems opted to house ODF with OASIS (Organization for the Advancement of Structured Information Standards), an international consortium that develops and promotes adoption of information standards. In 2002, the first meeting of the OASIS Open Office Technical Committee (TC) formalised the standardisation effort of ODF (OASIS ODF Adoption TC 2006). In 2005, ODF 1.0 was finalised (Brauer et al., 2005), and submitted for ratification to the International Standards Organisation (ISO); in 2006, this standard was ratified as ISO 26300 (ISO/IEC, 2006).

In its early incarnations, ODF was already a complex specification, amounting to approximately 700 pages (Durusau et al., 2006). Unlike existing Microsoft Office binary document formats, ODF utilized a wide range of existing data standards. An ODF document file utilized the standard ZIP compression format to group together a set of related document assets, simplifying transmission, archiving and dissemination. The contents of these packages, including text, document metadata, typesetting information, formulas, graphs, charts and animations, were specified using XML (eXtended Metadata Language), itself then a relatively new standard for representing data designed to improve interoperability between systems. In preparation for eventual ISO compliance, ODF also supported international character support and spacing (ISO/IEC, 2006).

ODF could therefore boast an impressive technological case against the incumbent opposition. The political case for an alternative to the Microsoft Office document format came with a landmark policy statement announced by the State of Massachusetts in 2005, that all documents created and archived by the state must be based on "open formats" (Commonwealth of Massachusetts, 2005). While ODF looked to be the leading open format candidate, as Shah et al. (2007) note, moves to promote ODF was to meet stiff opposition from 
a unlikely confederacy of parties: Microsoft itself, independent software vendors and disability groups, who complained about accessibility of the new proposed format. Partly as a consequence two key architects of the policy, the state's Administration and Finance Secretary, Erich Kriss, and CIO, Peter Quinn, later resigned (Shah et al., 2007). In 2007 the state's strong stance on ODF was ameliorated to include the emerging Microsoft standard, OOXML (Office Open XML) (Pepoli \& Dormtzer, 2007). This particular localised institutional intrigue foreshadowed the larger drama that attended the standardisation of OOXML itself.

\section{Microsoft Responds with OOXML}

Faced with the explicit challenge of ODF, which threatened to level the playing field of office software applications, Microsoft responded with its own standardisation effort around its then-fledgling XML-based format. Though regarded with some cynicism, this concession towards the standardisation of previously proprietary formats itself represented a marked change in attitude. For Microsoft, as with many other companies, the proprietary closed nature of its file formats had been a critical feature of its competitive market strategy. In Microsoft's case, protection of such intellectual property not only served its interests in the highly lucrative office software market; it also simplified its sales pitch for the Windows operating system and a range of subsidiary products, including development tools, database systems and emerging products in the enterprise, entertainment and online markets.

In the preceding decade, however, Microsoft had been under increasing threat partly as a result of its very success in establishing market dominance in the operating system and office software markets. Not only had zero-cost open source competitors like OpenOffice emerged, Microsoft had undergone a damaging US antitrust case between 1998 and 2002. In response to the threat of ODF and the broader changing climate of the IT industry, the company's tactics had to become more subtle: outwardly conciliatory without losing hold of its competitive advantage. In proposing an alternative standard, it was able to simultaneously trumpet the benefit of standards, while undermining a specific recently ratified de jure standard that might threaten market share and revenue. At least one respected commentator noted at the time that the company's new practices continued to pursue much the same ends of eliminating competition (P. Jones 2008b).

This shift towards greater document format interoperability had in fact begun much earlier, in 1999, with the release of Microsoft Office 2000. In that version documents could be saved in HTML format and published on the Internet (although these could be viewed only with considerable difficulty and lack of fidelity by nonMicrosoft browsers). With the release of the next version, Microsoft Office 2003, Word, Excel and PowerPoint documents could also be imported and exported in XML format. This was a far more significant step, as it meant the complete set of Office document features could be parsed and generated by third-party software for the first time (Lenz et al., 2004). These XML schemas were to form the basis for Microsoft's subsequent submission of a new open document format, termed Office Open XML (or OOXML), to Ecma International, a private member-based standards organisation, in December, 2005 (Ecma International 2008c). A year later, in December 2006, Ecma International approved the standard. By itself, this approval carried little weight, since the two chairs of the Ecma supervising technical committee were themselves senior Microsoft executives (Ecma International 2008b) ${ }^{1}$. However, the approval did mean that OOXML could now be submitted to ISO (International Organisation for Standards). Just as OASIS had shepherded ODF, Ecma International played a similar role with respect to OOXML - a kind of mirroring process similarly aimed towards rapid ISO ratification. In a final step aimed to solidify political support for OOXML, the next version of Microsoft Office allowed documents to be saved in the draft format. While still a proposed de jure standard - and unlike ODF - OOXML was already supported by the most popular office software in the world.

Microsoft had previously been accused and penalised, both in the US and Europe, for its heavy-handed competitive tactics. The development of OOXML showed a general shift towards exercise of institutional soft power, built around rhetorical and practical engagement with standards, interoperability and openness. The name "OOXML" itself functioned as a specifically signalling device, to show Microsoft's willingness to deliver open formats, but at the same time distracting attention from the still nascent ODF format, also bearing the term "open" in its name. This discursive move, along with the political mobilisation of Ecma International and partner companies to promote OOXML as an ISO standard, no doubt was intended to

\footnotetext{
${ }^{1}$ The population of technical committees by employees of the company promoting standards is not unusual - for example, the OASIS technical committee overseeing the development of the OpenDocument Format was similarly lead by employees of Sun Microsystems and IBM (OASIS, 2008).
} 
create confusion among general software users, inattentive to the nuances of complex document formats and their sponsors.

\section{Standardisation in Motion}

The Ecma International group, having previously approved the Office Open XML specification within its own member group, promptly submitted the specification to the ISO/IEC Joint Technical Committee (JTC) 1 on December 20, 2006. The JTC1 comprises 41 Participating Members, a subset of the total number of ISO National Bodies, and is charged with developing Information and Communication Technology standards. The submission was placed under the Fast-Track program, designed for rapid approval of existing standards, under the name of ISO/IEC DIS (Draft International Standard) 29500. An initial review period was conducted over the subsequent 30 days, during which any registered ISO members could submit "perceived contradictions" to the proposal to the JTC. Ecma responded to these comments on February 28, 2007 (Ecma International, 2007). A five month "letter ballot" period followed, leading up to a vote on September 2, 2007. The ISO regulations concerning the vote required a) that no less than $66.6 \%$ of the national bodies involved in the JTC itself approve the standard and b) that no more than $25 \%$ of the total national bodies disapprove (abstention is permitted) (ISO/IEC, 2004). The vote results, published in early September 2007, registered $53 \%$ of the 41 members participating in the JTC approved, while $26 \%$ of the overall 104 ISO member body disapproved (ISO, 2007). This narrow failure led to ISO making the unusual step of announcing that a Ballot Resolution Meeting (BRM) would be conducted at the ISO headquarters in Geneva, Switzerland, between the 25th and 29th of February, 2008 (ISO, 2008a). This in turn was to be followed with a final ballot on OOXML, 30 days later, on the 29th of March (ISO, 2008a). The BRM was designed as a forum for the standard submitter to respond to comments with possible amendments, and for the National Bodies to then re-vote on whether the amendments are sufficient to pass the standard.

In addition to the negative vote result itself, the National Body members raised a total of 3,522 comments. This extraordinary number of comments echoed and even quoted many criticisms voiced in online forums and blogs covering the case, suggesting that ISO members themselves were actively following discussions in the public sphere. The Ecma Technical Committee (TC45), alongside the ISO Project Editor, was tasked with formulating a series of proposed dispositions, or responses, to these comments. Both comments and dispositions were not subject to public scrutiny, according to ISO directives. Their general character could however be inferred from a Ecma press release, which outlined a relatively small number of substantive objections, along with recommended amendments to the OOXML proposal to incorporate them (Ecma International, 2008a). These recommendations were not binding upon the specification (ODF Alliance, 2008). They did however provide ISO members with suggested mechanisms for resolving objections at the BRM, in the hope of securing the required number of approval votes. Frustrations with the volume of comments that were not addressed led to members voicing their concerns through public channels (Sayer, 2008). The JTC reconvened in February 2008 at a Ballot Resolution Meeting, after which a follow-up, and final, vote on OOXML was held at the end of March. Table 2 highlight the major dates and events of OOXML standardisation process.

[Insert Table 2 here]

\section{Subverting Process: The Tactics of Corporatised Standardisation}

The apparent calm of the august and bureaucratic ISO procedures belies the turbulent undercurrents that swept through both the voting arrangements and subsequent preparation for the Ballot Resolution Meeting. Various parties were accused of interfering with the ISO voting process, and, as we discuss further, many of these accusations focus on the use of media, discourse and institutional mechanisms to influence ISO members. In turn we summarise these claims made against Microsoft, and against its opponents.

\section{“Interoperability... a Vital Concern"}

During the vote itself, a number of reports suggested that Microsoft played a significant, and sometimes insidious role in the deliberations of many national bodies. In Portugal, one attendee published transcripts of discussions within the technical committee preparing its vote (Seabra, 2007). These transcripts contain elements of high farce: there is a prolonged conversation about lack of chairs for Sun and IBM representatives; complaints of excessive numbers of Microsoft affiliates; and the attendee himself had problems being heard in a group of 25 (Seabra, 2007). Similar complaints of branch stacking also occurred 
elsewhere. In Sweden, Microsoft partners were introduced at the eleventh hour into the voting group, a breach of voting regulations severe enough to warrant Sweden's vote being recorded as an enforced abstention (Haverblad, 2007). Further reports were filed in blogs, open letters and the press outlining purported voting irregularities with other ISO members: Denmark (Orion, 2007), Italy (Updegrove, 2007), Malaysia (Kit, 2007), the Philippines (Schestowitz 2008), Switzerland, Germany, the Netherlands, and the US (Espiner, 2007). Such claims of infiltration and corruption remained uncorroborated, although the EU had considered taking Microsoft to court on the basis of the allegations of intrusion into ISO committees (Forelle, 2007), adding to two other ongoing cases of anti-trust litigation (European Union Directorate General Communication, 2008). Soon after the vote, two online studies attempted to demonstrate a significant correlation between, respectively, levels of corruption and GDP, and approval votes from ISO members, claiming that more corrupt and poorer countries were more likely to approve OOXML in the ISO ballot (Puolamäki, 2007; Hintjens, 2008). Such studies contributed to a perception of significant Microsoft intervention - through economic or other incentives - in those countries' voting procedures.

Further complaints arose about the ISO submission itself, both during and after the voting process. Several National Bodies complained about what could be termed a case of discursive obfuscation, involving both the volume of documentation covering the standard - 6,000 pages of specification, 3,500 comments lodged by the voting ISO members, followed by another 2,000 pages of amendments in response to the comments and the dubious merit of using a "Fast Track" process to review such a complex and lengthy standard (Ecma International, 2007). Since the initial 30-day review period, considerable attention focussed on whether OOXML was in fact duplicating the existing ISO/IEC 26300 standard - the ODF format (Ecma International, 2007). Concerns were also raised over the naming of the specification itself, variously called "Office Open XML" (OOXML) and "Open XML". Advocates of OpenDocument Format reiterated the fact that the names of the formats were intended to confuse non-specialists, particularly since the largest implementation of ODF had, since 2002, been named OpenOffice (Open Document Format Alliance, 2006). The Ecma group's legitimacy as a standards body was called also into question - co-authors of the OOXML specification appeared to include only two non-corporate entities, the British Library, and the Library of Congress - and seemed to be little more than an at arm's length vehicle for the promotion of Microsoft's fiscal interests (Kit, 2007). Rumours of Ecma voting membership costing \$57K USD reinforced the impression of a closed group of companies rubber-stamping each other's standards, rather than subjecting them to due scrutiny by other institutions and the general public (Weir, 2007).

Microsoft was also accused of both surreptitiously and overtly distorting public presentations and discussions of OOXML. In January 2007 Rick Jelliffe, a prominent author and developer of XML technologies, was contracted by Microsoft to “provide more balance on Wikipedia concerning ODF/OOXML” (Jelliffe, 2007). In spite of offering a nuanced defence of his position, a furore immediately erupted - 188 comments were posted in response to this post alone - over the subversion of the (always idealised) independence of Wikipedia content. A subsequent invitation by Standards Australia to invite Jelliffe to the Ballot Resolution Meeting a year later (Jelliffe, 2008) was met with further suspicion (NoOOXML, 2008). In 2009, the Wikipedia entry on OOXML included over several thousand changes and 50 discussion entries, the majority concerning various authorial biases around serial edits, corrections and amendments to the article.

Claims of distortion were also levied at Microsoft over perceived attempts to purchase preferential search results and positive press in IT journals and reports. A discussion on the ODF mailing list suggested Microsoft had paid for the term "OpenDocument" on the Google search engine, to confuse users searching for OpenDocument Format (Barrionuevo et al., 2008). In early 2010, a search for "OpenDocument” continued to present a sponsored link for "Open XML" (Google, 2010). More critically, a technical report released early in 2008 by the apparently independent Burton Group advocated use of OOXML over ODF, arguing:

Any organization... using Microsoft Office applications should plan to exploit OOXML...

ODF is insufficient for complex real-world enterprise requirements, and it is indirectly controlled by Sun Microsystems, despite also being an ISO standard... for now ODF should be seen as more of an anti-Microsoft political statement than an objective technology selection (O’Kelly \& Creese 2008).

The ODF Alliance quickly issued a rebuttal, complaining both of numerous technical inaccuracies and, more significantly, of the timing of the report, so soon before the ISO delegates were due to meet to vote in the Ballot Resolution Meeting in 2008 (ODF Alliance, 2008). This triggered further rounds of call-and-response from both camps, including an insinuation that one of the report's authors, Peter O’Kelly, stood to benefit 
through indirect remunerations via appearances at Microsoft trade shows (Weir, 2008). The report's coauthor responded that they had interviewed a range of companies in compiling the report, and had specifically refused corrections suggested by Microsoft, in order not to compromise neutrality (Creese, 2008).

Microsoft also appeared to be buying support for OOXML from smaller competitors. Novell, an early supporter of ODF, was accused of an about-turn when it announced development of an open source converter of ODF documents to OOXML. This followed a prior announcement in November 2006 that Microsoft and Novell would enter into a broad-ranging agreement involving technical, legal and marketing co-operation. As part of this agreement, Microsoft had pledged $\$ 450$ million to be spent over five years, and Novell agreed to drop litigation over patent infringement relating to their WordPerfect product (Weiss and Enck, 2006). Critics saw this as a continuation of Microsoft's practices of artificially propping up competition, as it had done in 1997 when it invested \$150 million USD in Apple (Kawamoto et al., 1997).

In a series of announcements and updates leading up to the BRM, Microsoft endeavoured to bolster its credentials in relation to the question of openness. In late 2006, it released the Open Specification Promise, an undertaking "not to assert any Microsoft Necessary Claims" against the development and use of implementation of "Covered Specifications" (Microsoft Corporation, 2008e). OOXML was listed as one of the specifications to be effectively released from patent rights. This was followed by the release of Microsoft Office binary formats under the same promise in early 2008 (Microsoft Corporation, 2008d). Six days later, and just four days before the BRM was due to convene, a high-powered delegation including the CEO, Steve Ballmer, senior vice-president and general counsel Brad Smith, and Chief Software Architect, Ray Ozzie, announced an astonishing series of "principles" and "actions" to promote interoperability and openness (Microsoft Corporation, 2008d). This announcement caused significant excitement in the blogging community following the case, with commentary either eulogising or decrying the announcement. Some were suspicious of the timing of this series of announcements, so close to the BRM (Updegrove, 2008c). Others acknowledged that the release of 30,000 pages of technical product documentation also represented a marked shift from the culture of secrecy and hostility that had pervaded the company in the previous decade. Ray Ozzie, then Chief Software Architect for Microsoft, accounted for this shift with the following somewhat genial narrative:

When a new type of product or technology is introduced, vendors tend to focus first and foremost on little more than whether or not their product satisfies an immediate customer need, and in these early stage products innovation tends to trump interoperability, data portability, or any such concerns. But as users put more and more of their data into these products, a new set of issues emerge... Issues such as document preservation and portability have become vital concerns for customers. Furthermore, as a direct byproduct of the Internet's ubiquity, virtually every system and product nowadays has become interconnected in some way to most everything else. And so interoperability between our systems has also become a vital concern (Microsoft Corporation, 2008f).

Microsoft also sought other means to counter the effects of negative perception and press surrounding OOXML. Several of its senior staff, including Brian Jones (Group Program Manager of the Office Solutions Framework), Gray Knowlton (Principal Group Program Manager, Microsoft Office), and Steve McGibbon (EMEA Regional Technology Officer), maintained active blogs devoted to technical and political aspects of OOXML standardisation. These were met with counter-posts from executives from other companies and members of various open source communities. Bob Weir (Senior Technical Staff Member and co-chair of the OASIS ODF Technical Committee) and Bob Sutor (Vice President of Open Source and Standards) at IBM were especially vocal in their responses to the Microsoft bloggers. The blogosphere offered a far more personal, direct and efficient means of influencing debate than conventional press releases and technical reports. Rather than simply adopting a company line, blog posts allowed these key individual actors to present highly nuanced point-by-point argument with their opponents. Blogs and other emerging social media forms posed risks, however, compared with institutionally controlled communication channels. Readers could answer back, and offer alternative views on other blogs. Critics created a number of hostile blogs specifically dedicated to covering OOXML, with provocative titles such as "NoOOXML", "Boycott Novell” and "OOXML Hoaxes”. Two blog authors covering general legal aspects of information technology, Pamela Jones (Groklaw) and Andy Updegrove, also devoted considerable critical attention to OOXML. A network of cross-referenced blog posts, from these and other authors, dissected and analysed the specifics of the OOXML specification, as well as reported on the distortion of the ISO voting process. Such criticisms were echoed in the press, in online forums and even in specific comments by ISO voting members, showing 
that the blogosphere had emerged as a new and decidedly risky discursive terrain in the battle for institutional and public opinion.

\section{Standards as "Strategic Weapons"}

Blogs were among a number of the rhetorical vehicles Microsoft's opponents deployed to undermine OOXML. Just as Microsoft galvanised the many parts of its formidable public relations machine, defenders of the OpenDocument Format were equally indefatigable in making the opposing case. Between 2005 and 2008, the ODF mailing list witnessed average traffic of four emails a day; this rising in intensity around key events like the ISO ballot result itself. Like Microsoft, ODF proponents were engaged in active Wikipedia editing of both OOXML and ODF articles (though, it must be said in relation to the OOXML pages, these biases appeared to be more obvious), as well as significant commentary on Microsoft employee blogs, forums, and elsewhere.

Microsoft frequently took it upon itself to complain about the underhand tactics of corporate rivals who seemed to be destabilising the process of OOXML ratification. In the lead-up to the Ballot Resolution Meeting in early 2008, Brian Jones complained that Rob Weir had been flown by IBM to various ISO national body groups in an attempt to lobby against OOXML (B. Jones 2008). Gray Knowlton analysed each of Rob Weir's posts on OOXML, concluding that out of 134 posts, "94 of those posts have a central antiOpen XML and/or anti-Microsoft theme” (Knowlton, 2008). That IBM - not Sun, nor any other parties seemed to be co-ordinating the obstruction of the OOXML standardisation process, according to Microsoft, is made clear in an article in the popular technology magazine, ZDNet. Provocatively entitled "Microsoft: IBM masterminded OOXML failure", it quotes several senior Microsoft employees in a telling series of statements:

"Let's be very clear,” Paoli said. "It has been fostered by a single company - IBM. If it was not for IBM, it would have been business as usual for this standard."

...

"IBM have asked governments to have an open-source, exclusive purchasing policy,” Tsilas said.

"Our competitors have targeted this one product - mandating one document format over others to harm Microsoft's profit stream."

"It's a new way to compete," Tsilas said. "They are using government intervention as a way to compete. It's competing through regulation, because you couldn't compete technically” (Winterford, 2008).

On his blog Steve McGibbon also pointed to the strategic use Sun makes of standards as a means of achieving commercial goals:

Interesting May 2006 article on IEC's website that I haven't seen before in which Michelle Aden, Sun's “Standards Strategy Ambassador for the Chief Technologists's [sic] Office” explains how standards are:-

... a "strategic weapon" in her company's arsenal. "Those who prepare standards," she explains, "have a competitive advantage because their ideas are being standardized" (McGibbon, 2008b).

The involvement of Sun Microsystems and IBM was criticised from other quarters as well. The OpenDocument Foundation, a technology advocacy group set up to promote ODF, suddenly reversed its stance. In mid-2007 the group announced publicly it no longer supported ODF, claiming it had been coopted for purely commercial ends by Sun Microsystems. The Foundation's support for yet another document standard, the CDF, led to a long series of heated exchanges on the ODF mailing list. In part due to the ambiguous name of the Foundation itself, it eventually disbanded. Nevertheless its members, through various blogs, remained sceptical of Sun's active steerage of the ODF format as much as of Microsoft's promotion of OOXML, and instead advocated hybridised forms of HTML as the superior alternative to both formats.

Then, in the lead up to the Ballot Resolution Meeting, yet another “Open” group emerged. The OpenForum Europe - a loose affiliation of companies and individuals - held a rival conference coinciding with the BRM itself, and held in the same convention centre in Geneva (Brown, 2008b). This second event was criticised for intentionally disrupting the BRM, staged for political purposes to confuse and provoke ISO delegates. Its 
political purpose became clear when it was announced that keynote addresses were to be delivered by noted opponents of OOXML, representatives from Google (Vint Cerf - a celebrated pioneer of the Internet) and IBM (Bob Sutor, another vocal critic of OOXML). The convenor of the BRM, Alex Brown, complained "It seems the OpenForum Europe is organising a meeting to coincide with the BRM: same time, same venue. It's not clear from the announcement what time of day this seminar is scheduled to take place, though an invitation is issued to BRM attendees" (Brown,2008b).

This complicated set of discursive moves by Microsoft and its competitors largely revolved around claiming the ground of openness: ODF, OOXML, the Open Specification Process, OpenForum Europe and even purchasing advertising space on search engines that reference the term open all were efforts to own a brand, to reinforce perceptions that one company or product or standard was more "open" than another. Ironically the production of such discourse itself opened the doors on the complex political process that technical standards undergo. But it also offered something new, not seen at the same scale before in the many standards published by ISO and other standards organisations: individual voices, both inside and outside institutional boundaries, representing corporate, governmental, standards bodies and communities, engaged in something of a dialogue over the merits of a document format that was both technically obtuse and highly pervasive.

\section{End-game? BRM and final vote result}

Given the intrigue of the lead-up to the BRM final vote, the end-game of the controversy proved to be anticlimactic. The vote itself failed to provide a clear-cut result, with both sides calling victory. In a frenetic 4 day session, from the 25th to the 28th of February 2008, the Ballot Resolution Meeting attempted to sift through an overwhelming number of revisions and comments on the original proposal (Hogarth, 2008). The majority of these, over $80 \%$, were ignored or cursorily dealt with, to the dismay of many attendees and commentators (Bray, 2008; Hogarth, 2008; Silva, 2008; Updegrove, 2008b). A further 30-day voting period was organised, during which members could agree or disagree with the remaining revisions. A successful vote on these revisions would overturn the previously unsuccessful vote on the proposal itself. Blogging and mailing list activity spiked over the month of March, as speculation mounted over the direction ISO voting members would take.

By the 30th of March, a number of previously dissenting votes had now agreed to the revisions, ushering in DIS 29500 as a new ISO standard. Three days later, the ISO committee tersely announced the approval via press release: "ISO/IEC DIS 29500, Information technology - Office Open XML file formats, has received the necessary number of votes for approval as an ISO/IEC International Standard” (ISO, 2008c). This time, $75 \%$ of the participating national body votes were in favour of the standard, while $14 \%$ of the total national body votes were negative (ISO, 2008c). In anticipation, Microsoft had issued a self-congratulatory press release a day earlier - on April Fool's Day - and shortly after, a number of bloggers active in the lead-up to the vote were busy dissecting the results (Microsoft Corporation, 2008a). Brazil, India, South Africa and Venezuela later appealed the decision on varied grounds, including:

- Failure to address contradictions

- Failure to meet ISO guidelines and directives

- Failure to publish BRM decisions and other documents

- Failure to protect the voting process from interference by multinational corporations

- Problems with handling the size of the specification within the scope of the fast-track process

Confidential details of the objections - and the internal recommendations to the ISO Technical Management Board, by the CEO's of ISO and IEC respectively, to ignore the objections - were obtained independently by two prominent bloggers in early July (P. Jones, 2008a; Updegrove, 2008a). No further action was taken, and the appeals were quietly rejected by yet another round of voting in mid August (Updegrove, 2008b). Finally, in November 2008 the complete and amended ISO/IEC 29500:2008 specification was published, and made freely available (ISO, 2008d). The set of four documents comprising the amended standard amounted to 7,234 pages (not including associated technical electronic inserts).

At the point of publication no software system - including any edition of Microsoft Office - supported the new ISO standard. In May 2008, Microsoft announced, ironically, that its current version of Microsoft Office, would support ODF, while only the next version would be compliant with OOXML (Microsoft Corporation 2008c). In practice, OOXML was quickly to become the default format of Microsoft Office, making it far more widely used than its rival format. Microsoft also undertook a series of further moves to underline its 
commitment to openness and document interoperability: it joined the OASIS ODF Technical Committee (McGibbon 2008a); it joined IBM and others as a co-funder of the Apache Software Foundation, a loose consortium devoted to open source software; it extended its Open Specification Promise to include software developed under a GNU Public License (GPL) (Microsoft Corporation, 2008e; P. Jones, 2008b); and it sought to contribute to and release a number of open source projects. These steps, however opportunistic, also underscored Microsoft's commitment to openness, and ultimately served to complicate the characterisation of Microsoft as solitary villain of the document formats narrative. The original ratification of ODF initiated a chain of events that meant the world's largest developer of office software had to ensure its own formats would become standards-compliant in some sense.

\section{Aftermath and Analysis}

One Microsoft blogger noted in relation to the support for ODF, “[OpenXML \& ODF] never was a zero sum game - it was always about customers winning” (McGibbon, 2008a). A more adequate description of the controversy would point to a complex series of institutional stakes and pay-offs, played out through range of formal and informal discursive mechanisms. Certainly the ISO organisation itself has had to defend itself against a highly public and critical campaign - a series of press releases, and the publication of a long interview with the CEO, Alan Bryden, in June 2008, tried to arrest what amounted to a public relations disaster for an organisation that publishes more than 100 standards every month (ISO, 2008b). Collaborators of the ODF standard have since had to worry about working alongside wolves in sheep's clothing at the specification drafting table. Microsoft itself invested enormous resources in the complex process of authoring, distributing, marketing and implementing a vast specification that is unlikely ever to see largescale uptake by rival products in the foreseeable future. And customers - governments, companies and individuals alike, the supposed beneficiaries of standardisation - also needed to contend with what is at least a vexing choice between two largely overlapping ISO document format standards. Moreover new avenues had begun to emerge to challenge the very technological premise of a document format: as Rob Weir, CoChair of the OASIS ODF Technical Committee, noted at the time (2009), the growth of online collaboration tools such as blogs, wikis and new online office suites such as Google Drive and Zoho Office were making, in some market segments at least, the office software suite increasingly redundant.

In the aftermath, the convenor of the BRM, Alex Brown noted:

2008 has been an exciting year for document format standards. 2009 will, I predict, be rather more boring. (Brown, 2008a)

The controversy over electronic document formats - specifically, over whether OOXML should have been admitted as a separate standard - has, since 2008, subsided considerably. Signs of the "boring” process of document format standardisation is evident in the nature of discussions on blogs and mailing lists since 2009, which have largely focused instead on technical issues of concordance, conversion and interoperability between ODF and OOXML. Mainstream IT press and blogosphere attention has since moved on to other technological places of competitive contestation - cloud computing, mobile devices, social networking - and other standards have emerged. As of 2013, Microsoft Office remains the dominant desktop office suite, and OOXML - more familiar in the form of .docx, .xlsx and .pptx extensions to file names - has continued to eclipse ODF in practical use, by an order of magnitude. OpenOffice remains an important but still niche competitor, now hosted by the Apache Foundation. Google Drive (formerly Google Docs) has since emerged as the most likely potential disruptive technology to Microsoft's hegemony of the office suite market. At least notional support for ODF and OOXML is common to all three products, although seamless interoperability remains a problem.

However the case leaves open broader questions about the purpose and processes of IT standardization. Such standards have historically been offered as institutional protections against the fragmentation of products and services, and the corresponding issue of vendor lock-in. Standards-compliance, brokered by independent bodies, helps solve a problem of informational asymmetry between producers and consumers in relation to information technology commodities. When standards themselves become beholden to given corporate interests in near-monopolistic situations, costs associated with compliance instead serve as effective corporate levies, penalising rather than protecting consumers. The case of DIN 29500, OOXML, exemplifies this situation. As a former convenor of the ISO/IEC JTC1 noted in a telling statement, "The days of open standards development are fast disappearing. Instead we are getting 'standardization by corporation'” (Bryan, 2007). 
Indeed the controversy operates as a virtual handbook in tactics for mounting a "standardisation by corporation" operation. A variety of discursive strategies had been deployed to bolster institutional cases both for and against OOXML. Both Microsoft and its ODF adversaries were accused of name obfuscation (notably in the name of OOXML itself); "fast-tracking” vast and complex technical specifications and amendments; branch-stacking voting member groups; sponsoring "independent” reports and articles; artificially supporting competitors; and effectively conducting large-scale astroturfing campaigns under various forms of "open” monikers.

Yet the controversy also exhibits a rare kind of openness in a different sense, in that it perhaps paves the way towards new forms of standardisation processes. The corporate use of blogs, wikis and social media offer important discursive adjuncts to conventional fare of press releases, annual reports and technical documentation. The shift towards online media has meant, in this case, that independent commentators, open source advocates, customers are no longer merely an audience observing the standardisation processes but can enter the stage as actors and participate, at least to some degree, in standardisation processes. More tellingly, existing actors - technical and legal experts, meeting convenors, committee members - were given voice beyond their conventional roles behind corporate walls or closed meetings. While no panacea, the very public profile of the controversy itself, as well as the wide range of views disseminated through online media, do point to, potentially, a new form of open standards development, where a diversity of interests are able to be represented in an online public sphere. As we suggest in our Introduction, this is partially evident in the ways standard bodies such as ISO have sought to engage broader audiences in standards development, review, education and use through social media channels such as Facebook and Twitter, along with dedicated online channels such as Consumers International (2013). ISO also has specifically worked to include developing countries in standards development, addressing some of the concerns raised in the OOXML debate (ISO, 2013). However actual participation in ISO voting procedures remains limited to members of national standards bodies, typically individuals nominated and recommended from corporate and government institutions (see for example Standards Australia, 2011). More suggestive of how software standards development might meet the criterion of procedural and discursive openness are examples of lightweight document formats such as reStructuredText and Markdown, where both specifications and supporting implementations are released with open source and public domain licensing conditions, and where online collaborative tools are foundational to their development.

\section{Conclusion}

Standards exist, at least in part, to protect public goods from abrogation by private interests (Dolmans, 2010). Undue influence by a single vendor can limit the openness of standards and the feasibility of competition, even when the apparent result is the competitiveness implied by multiple standards. This in turn stifles innovation, limits consumer choice, increases costs and undermines the durability of standards (Egyedi \& Koppenhol, 2010). The case of the standardization of both ODF and OOXML document formats between 2005 and 2008 has demonstrated the sub-optimality of standardization under these conditions. Ironically the outcome was in part preempted by the lack of genuine engagement with Microsoft from the ODF standards development group at the outset. To a degree, the rules of the game that govern strategic patterns of competition and co-operation in corporate inter-institutional arrangements - a theme that runs through both old and new institutionalist theorisations - are here more culpable than the specific malfeasance of a single institutional actor. In spite of its flaws, however, the very controversial and public nature of the discourse surrounding the standardization of OOXML, largely abetted by online blogging and commentary, had unanticipated side effects: it forced far wider recognisation of the weaknesses inherent in standardization processes, including the complex coupling of corporate, government and other institutional actors. This very publicity, and the skepticism it has induced in the broader technology community towards committee standards bodies such as ISO, provides impetus and potential for greater openness and transparency of standardization processes in future.

These two features - institutional interference with standards setting processes, and the role of discourse in bringing that interference into greater public scrutiny - also suggest discourse analysis is an increasingly useful tool for understanding standards setting processes and the interests they serve. The controversy exhibits many of the features often ascribed to "institutions behaving badly", particularly in the case of Microsoft, one of the world's largest corporations. On the other hand, emerging forms of online discourse serve to show how different actors, representing both corporations and a disparate array of other organizational and social types, can offer reasons and explanations that complicate a purely critical narrative of given institutional practice. Such discourse offers transformative potential with respect to two kinds of 
institutions: corporations, as both Microsoft and its adversaries had been encouraged to convert proprietary formats on the basis of emerging discourses of "open standards"; and of the standards bodies like ISO, which in this case has witnessed a venerable veneer of expert authority wither under the scrutiny of prolonged public critique. Whether this eventuates in future standards that better represent the interests of their sponsoring organizations and, more pertinently, the broader public remains to be seen. As Fountain (2011) has noted, information technology frequently serve to strengthen rather than weaken institutional holds on public goods such as standards. This case does however reflect the increasingly dynamic and unpredictable nature of standards setting processes.

This dynamism holds several implications for standards development, especially with respect to standards that relate to consumer applications such as word processors, rather than technical infrastructure such as networks, hardware and communication protocols. The first of these is the relative transiency of what might be considered information technology application types or categories. The intervening five years since the ratification of OOXML have witnessed marked shifts in consumer computing habits through the use of phones, tablets and other devices. The difficulty Microsoft has faced in making inroads in these markets shows its dominance of desktop application software has not been significant in determining consumer preferences for either these types of devices or the software that runs on them. While such devices are purportedly primarily for the consumption rather than creation of content, the large number and prominence of note-taking products on both Apple and Google app stores suggests the habits and tools for authoring documents is diversifying rapidly. Few of these products promote compatibility with either ODF or OOXML. Instead new document formats, such as Markdown, HTML5 and JSON, have emerged through the open source community, offering lightweight syntaxes and specifications. The office suite market has, in some way then, begun to devolve into a far more fragmented state from a recent high point of consensus around merely - two competing document standards. Though driven by a broader shift in computing, it is tempting to see this trend as a something of a rebuttal by both software developers and users to the technical and institutional complexities of ODF and OOXML.

The second and related feature is the emergence of a genuinely globalized software industry, and its impacts on standardization efforts. This particular case had hallmarks of contestation between US and European interests - though ODF was strongly backed by rival US corporations, complaints over due process were most bitter from European ISO members. However there are current signs that in Asia particularly, vendors are moving increasingly from hardware to software and services. The current competition between Apple and Samsung, for instance, in the mobile phone market is strongly marked by regional distinctions, with Samsung especially dominant in the Asian market. This competition is determined by device capability and cost, but also by "soft" features of devices, such as usability and application support. Future standardization processes in areas like document formats will increasingly be marked by a greater diversity of institutions, representing this globalized spread of both software producers and consumers.

The third implication concerns the future role of social media and other participatory mechanisms in standard setting processes. In this case, outside actors were able to exert various kinds of influence through advocacy on blogs and mailing lists. The continued growth of online social media in recent years, extending from blogging to other platforms like Facebook and Twitter, makes for a context in which a broader range of organizational and individual actors are able to exert influence on standards formation. This poses risks: the very character of "institutions" becomes harder to discern, and those actors need to be attentive to questions of identity, authenticity, and affiliation. Who is speaking in a given online forum? Whose interests are being represented? In an era of pervasive communicative anonymity, astro-turfing and trolling, such questions are increasingly difficult to resolve. In spite of these risks, the use of social media does suggest new ways in which standards setting bodies can "de-institutionalise" how standards come into being: by encouraging broader critical debate, and more democratic and participatory processes. At least for document formats, if the previous two trends continue - towards smaller, more "agile" and lightweight de facto standards, and with a greater global diversity of interests to accommodate - a broader, cheaper and more inclusive model for de jure standards development may be essential. The irony of the OOXML case would then be that it catalyses the case for information technology itself to play a vital role in ensuring the standards for its use and adoption are public goods - and remain open, as both products and processes.

\section{Acknowledgements}

We would like to thank the anonymous reviewers for their insightful remarks and contributions. Parts of this research were supported under Australian Research Council's Linkage Projects funding scheme (project 
number LP0667834).

\section{References}

Amaeshi, K. (2011), “International Financial Institutions and Discursive Institutional Change: Implications for Corporate Social Responsibility In Developing Economies”, Journal of Change Management, Vol. 11 No. 1, pp.111-128.

Arts, B. and Buizer, M. (2009), “Forests, discourses, institutions”, Forest Policy and Economics, Vol. 11 Nos. 5-6, pp.340-347.

Barrionuevo, A., Nooden, L. and Puttick, C. (2008), "Microsoft has purchased 'OpenDocument' in Google”, available at: http://lists.opendocumentfellowship.com/pipermail/odf-discuss/2008-

February/007107.html (accessed 4 September 2012).

Blind, K. (2011), “An economic analysis of standards competition: The example of the ISO ODF and OOXML standards”, Telecommunications Policy, Vol. 35 No. 4, pp.373-381.

Brauer, M., Durusau, P., Edwards, G., Faure, D., Magliery, T. and Vogelheim, D. (2005), “Open Document Format for Office Applications (OpenDocument) v1. 0", available at: http://www.oasisopen.org/committees/download.php/12572/OpenDocument-v1.0-os.pdf (accessed 4 September 2012).

Bray, T. (2008), “BRM Narrative”, available at:

http://www.tbray.org/ongoing/When/200x/2008/02/29/BRM-narrative (accessed 4 September 2012).

Brown, A. (2008a), “OOXML Gets Boring”, available at: http://www.adjb.net/post/OOXML-getsboring.aspx (accessed 4 September 2012).

Brown, A. (2008b), “OOXML: DIS 29500 Ballot Resolution Meeting (BRM) Approaches”, available at: http://www.adjb.net/index.php?entry=entry080107-183411 (accessed 4 September 2012).

Bryan, M. (2007), "Report on WG1 activity for December 2007 Meeting of ISO/IEC JTC1/SC34/WG1 in Kyoto”, available at: http://www.jtc1sc34.org/repository/0940.htm (accessed 4 September 2012).

Cargill, C.F. (2011), "Why standardization efforts fail”, Journal of Electronic Publishing, Vol. 14 No. 1, available at: http://quod.lib.umich.edu/j/jep/3336451.0014.103?rgn=main;view=fulltext (accessed 11 September 2012).

Clarkson, G., Jacobsen, T.E. and Batcheller, A.L. (2007), "Information asymmetry and information sharing”, Government Information Quarterly, Vol. 24 No. 4, pp.827-839.

Commonwealth of Massachusetts (2005), “CIO Meeting Notes, October 27 (2005)”, available at: http://www.consumersinternational.org (accessed 4 September 2012).

Consumers International (2013), “Consumers International - The Global Voice for Consumers”, , available at: http://www.mass.gov/anf/research-and-tech/it-serv-and-support/application-serv/openinitiatives/opendocument/cio-meeting-notes-october-27-2005.html (accessed 31 August 2013)

Creese, G. (2008), “Burton Group’s Response to the ODF Alliance (Part 1)”, available at: http://ccsblog.burtongroup.com/collaboration_and_content/2008/02/burton-groups-r.html (accessed 4 September 2012).

Czarniawska, B. and Mazza, C. (2013), “Consulting University: A Reflection from Inside”, Financial Accountability \& Management, Vol. 29 No. 2, pp.124-139. 
Czarniawska-Joerges, B. (1995), "Narration or science? Collapsing the division in organization studies”, Organization, Vol. 2 No. 1, pp.11-33.

David, P.A. and Shurmer, M. (1996), "Formal standards-setting for global telecommunications and information services. Towards an institutional regime transformation?”, Telecommunications Policy, Vol. 20 No. 10, pp.789-815.

Dolmans, M. (2010), “A Tale of Two Tragedies - A plea for open standards”, International Free and Open Source Software Law Review, Vol. 2 No. 2, pp.115-138.

Durusau, P., Brauer, M. and Oppermann, L. (2006), “Open Document Format for Office Applications (OpenDocument) v1.1, Committee Specification 1.1, 19 Oct 2006”, available at: http://www.oasisopen.org/committees/download.php/20847/OpenDocument-v1.1-cs1.pdf (accessed 4 September 2012).

Ecma International (2007), “National Body Comments from 30-Day Review of the Fast Track Ballot for ISO/IEC DIS 29500 (ECMA-376) 'Office Open XML File Formats’”, available at: http://www.ecmainternational.org/news/TC45_current_work/Ecma responses.pdf (accessed 4 September 2012).

Ecma International (2008a), “Proposed dispositions for National Body comments on DIS 29500 complete New phase to begin", available at: http://www.ecmainternational.org/news/TC45 current work/Proposed\%20dispositions\%20for\%20National\%20Body\% 20comments\%20on\%20DIS\%2029500\%20complete.htm (accessed 4 September 2012).

Ecma International (2008b), “TC45 - Office Open XML Formats”, available at: http://www.ecmainternational.org/memento/TC45.htm (accessed 4 September 2012).

Ecma International (2008c), “What is Ecma International”, available at: http://www.ecmainternational.org/memento/index.html (accessed 4 September 2012).

Egyedi, T.M. and Blind, K. (2008), The Dynamics of Standards, Edward Elgar Publishing, Cheltenham, UK.

Egyedi, T.M. and Koppenhol, A. (2010), “The Standards War Between ODF and OOXML: Does Competition Between Overlapping ISO Standards Lead to Innovation?”, International Journal of IT Standards and Standardization Research, Vol. 8 No. 1, pp.49-62.

Espiner, T. (2007), "Microsoft Accused of Rigging OOXML Votes: News: Business”, ZDNet, available at: http://www.zdnetasia.com/news/business/0,39044229,62031663,00.htm (accessed 4 September 2012).

European Union - Directorate General Communication (2008), “Antitrust: Commission initiates formal investigations against Microsoft in two cases of suspected abuse of dominant market position”, available at: http://europa.eu/rapid/pressReleasesAction.do?reference=MEMO/08/19 (accessed 4 September 2012).

Fairbrass, J. (2011), "Exploring Corporate Social Responsibility Policy in the European Union: A Discursive Institutionalist Analysis”, JCMS: Journal of Common Market Studies, Vol. 49 No. 5, pp. 949-970.

Fairclough, N. (1993), “Critical Discourse Analysis and the Marketization of Public Discourse: The Universities”, Discourse \& Society, Vol. 4 No. 2, pp. 133-168.

Flyvbjerg, B. (1998), Rationality and power: Democracy in practice, University of Chicago Press, Chicago, IL.

Forelle, C. (2007), “Microsoft's Office Push Scrutinized by EU”, The Wall Street Journal, available at: http://online.wsj.com/article/SB120242867034452081.html?mod=hps us my companies (accessed 4 September 2012). 
Foucault, M. (1980), Power/knowledge: Selected interviews and other writings, 1972-1977, Pantheon, New York.

Fountain, J.E. (2001), "Building the virtual state: Information technology and institutional change” Brookings Institution Press, Washington, D.C.

Fountain, J. (2011), “Disjointed Innovation: The Political Economy of Digitally Mediated Institutional Reform”, available at http://ssrn.com/abstract=1916392 (accessed 30 July 2013).

Ganesh, J. (2010), "Competition and cooperation in the formation of information technology interoperability standards: A process model of Web services core standards”, in Kaleidoscope: Beyond the Internet? Innovations for Future Networks and Services, 2010 ITU-T. Pune, pp. 1-8.

Ghosh, R. (2011), “An Economic Basis for Open Standards”, in DeNardis, L. (Ed.), Opening Standards: The Global Politics of Interoperability, MIT Press, Cambridge, MA, pp.75-96.

GitHub (2013), “GitHub Flavored Markdown”, available at: https://help.github.com/articles/github-flavoredmarkdown (accessed 31 August 2013).

Google (2010), “opendocument - Google Search”, available at: http://www.google.com.au/search?rlz=1C1CHNG_enAU346AU346\&sourceid=chrome\&ie=UTF$\underline{8 \& q=o p e n d o c u m e n t}$ (accessed 19 January 2010).

Granovetter, M. (1985), "Economic action and social structure: the problem of embeddedness”, American Journal of Sociology, pp.481-510.

Grøtnes, E. (2009), “Standardization as open innovation: two cases from the mobile industry”, Information Technology \& People, Vol. 22 No. 4, pp.367-381.

Hacking, I. (2004), "Between Michel Foucault and Erving Goffman: between discourse in the abstract and face-to-face interaction”, Economy and Society, Vol. 33 No. 3, pp.277-302.

Haverblad, K. (2007), “The Swedish OOXML Vote has been Declared Invalid!”, OS2 World.com, available at: http://www.os2world.com/content/view/14874/2/ (accessed 4 September 2012).

Hintjens, P. (2008), “Influence of Per-capita GDP on the ISO OOXML Vote”, available at: http://digistan.wdfiles.com/local--files/report:ooxml-vsgdp/Digistan:\%20OOXML\%20and\%20GDP.pdf (accessed 4 September 2012).

Hogarth, J. (2008), "How to buy a standard in 10 days", available at: http://www.tideway.com/community/blog-post/how-to-buy-a-standard-in-10-days/ (accessed 4 September 2012).

ISO (2008a), "Ballot resolution meeting on ISO/IEC DIS 29500 standard”, available at: http://www.iso.org/iso/pressrelease.htm?refid=Ref1114 (accessed 4 September 2012).

ISO (2008b), “Full Text of Interview of ISO Secretary-General by Reuters on ISO/IEC 29500”, available at: http://www.iso.org/iso/pressrelease/interview_iso_secretary-general_iso29500.htm (accessed 4 September 2012).

ISO (2008c), “ISO/IEC DIS 29500 Receives Necessary Votes for Approval as an International Standard”, available at: http://www.iso.org/iso/pressrelease.htm?refid=Ref1123 (accessed 4 September 2012).

ISO (2008d), "Publication of ISO/IEC 29500:2008, Information technology - Document description and processing languages - Office Open XML file formats", available at: http://www.iso.org/iso/pressrelease.htm?refid=Ref1181 (accessed 4 September 2012). 
ISO (2007), "Vote closes on draft ISO/IEC DIS 29500 standard”, available at:

http://www.iso.org/iso/pressrelease.htm?refid=Ref1070 (accessed 4 September 2012).

ISO (2013), “International Organisation for Standardisation”, available at: http://www.iso.org/iso/home.htm (accessed 31 August 2013).

ISO/IEC (2006), “ISO/IEC 26300:2006 - Information technology - Open Document Format for Office Applications (OpenDocument) v1.0", available at:

http://standards.iso.org/ittf/PubliclyAvailableStandards/c043485_ISO_IEC 26300 2006(E).zip

(accessed 4 September 2012).

ISO/IEC (2004), "Procedures for the technical work of ISO/IEC JTC 1., (3.0)”, available at: http://isotc.iso.org/livelink/livelink/7079667/_Part_1_Procedures_for_the_technical_work_5th_ed. ZIP archive ?func=doc. Fetch\&nodeid=7079667 (accessed 4 September 2012).

Jain, R. (2012), “Pragmatic agency in technology standards setting: The case of Ethernet”, Research Policy, Vol. 41 No. 9, pp.1643-1654.

Jelliffe, R. (2007), “An interesting offer: get paid to contribute to Wikipedia”, O’Reilly Media, available at: http://www.oreillynet.com/xml/blog/2007/01/an interesting offer.html (accessed 4 September 2012).

Jelliffe, R. (2008), “Mr Jelliffe goes to Geneva”, O’Reilly Media, available at: http://www.oreillynet.com/xml/blog/2008/02/mr_jelliffe_goes_to_geneva.html (accessed 4 September 2012).

Jones, B. (2008), “Is it jetlag?”, available at: http://blogs.msdn.com/brian jones/archive/2008/02/01/is-itjetlag.aspx (accessed 4 September 2012).

Jones, P. (2008a), "ISO to TMB: Here Are the Appeals Against OOXML; They Should Be Denied Updated 2Xs - Responses", available at:

http://www.groklaw.net/article.php?story=2008070907285710 (accessed 4 September 2012).

Jones, P. (2008b), “Microsoft Updates Open Specification Promise to Include GPL/Gives \$ to Apache Updated 2 Xs", available at: http://www.groklaw.net/article.php?story=20080725152355696 (accessed 4 September 2012).

Katz, M.L. and Shapiro, C. (1985), “Network Externalities, Competition, and Compatibility”, The American Economic Review, Vol. 75 No. 3, pp. 424-440.

Kawamoto, D., Heskett, B. and Ricciuti, M. (1997), "MS to invest \$150 million in Apple”, CNET, available at: http://news.cnet.com/2100-1001-202143.html (accessed 4 September 2012).

Kit, Y. (2007), “Open Malaysia: Microsoft turns its wrath to Malaysian Ministries”, available at: http://www.openmalaysiablog.com/2007/08/microsoft-turns.html (accessed 18 January 2010).

Knowlton, G. (2008), “Gray Matter: Got FUD? Here’s a guide for the perplexed”, available at: http://blogs.technet.com/gray_knowlton/archive/2008/02/04/got-fud-here-s-a-guide-for-theperplexed.aspx (accessed 4 September 2012).

Krechmer, K. (2006), “Open Standards Requirements”, International Journal of IT Standards \& Standardization Research, Vol. 4 No. 1, pp. 43-61.

Krechmer, K. (2011), “Open Standards: Definition and Policy”, in DeNardis, L., (Ed.). Opening Standards: The Global Politics of Interoperability, MIT Press, Cambridge, MA, pp. 219-238. 
Lai, E. (2007), “Will Symphony Play Taps for Sun's StarOffice Ambitions?”, Computerworld, available at: http://www.computerworld.com/action/article.do?command=viewArticleBasic\&articleId=9053679 (accessed 4 September 2012).

Latour, B., \& Woolgar, S. (1979), Laboratory life: The social construction of scientific facts, Princeton University Press, Princeton, NJ.

Lauber, V. and Schenner, E. (2011), “The struggle over support schemes for renewable electricity in the European Union: a discursive-institutionalist analysis”, Environmental Politics, Vol. 20 No. 4, pp. 508527.

Lenz, E., Laurent, S.S. and McRae, M. (2004), Office 2003 XML, O’Reilly Media, Sebastopol, CA.

McGibbon, S. (2008a), “OpenXML \& ODF was Never a Zero-Sum Game”, available at: http://notes2self.net/archive/2008/05/21/openxml-amp-odf-was-never-a-zero-sum-game.aspx (accessed 18 January 2010).

McGibbon, S. (2008b), “Sun: Standards as ‘strategic weapon’”, available at: http://notes2self.net/archive/2008/01/31/sun-standards-as-quot-strategic-weapon-quot.aspx (accessed 17 April 2009).

Maggio, D.P and Powell, W.W. (1983), “The Iron Cage Revisited: Institutional Isomorphism and Collective Rationality in Organizational Frields”, American Sociological Review, Vol. 48 No. 2, pp.147-160.

Mergel, I., Schweik, C. and Fountain, J. (2009), “The transformational effect of Web 2.0 technologies on government”, available at http://papers.ssrn.com/sol3/papers.cfm?abstract_id=1412796 (accessed 30 July 2013).

Microsoft Corporation (2008a), "Ecma Office Open XML Document Format Appears to Win Approval as an ISO/IEC Standard”, available at: http://www.microsoft.com/presspass/press/2008/apr08/0401OpenXMLVotePR.mspx (accessed 4 September 2012).

Microsoft Corporation (2008b), “Form: 10-Q, Received: 01/24/2008 16:18:17”, available at: http://www.shareholder.com/visitors/activeedgardoc.cfm?f=rtf\&companyid=MSFT\&id=5668908 (accessed 4 September 2012).

Microsoft Corporation (2008c), "Microsoft Expands List of Formats Supported in Microsoft Office”, available at: http://www.microsoft.com/Presspass/press/2008/may08/05-21ExpandedFormatsPR.mspx (accessed 4 September 2012).

Microsoft Corporation (2008d), “Office Binary File Formats (for Word, Excel and PowerPoint) - Published February 15, 2008”, available at: http://www.microsoft.com/interop/docs/OfficeBinaryFormats.mspx (accessed 4 September 2012).

Microsoft Corporation (2008e), “Microsoft Open Specification Promise”, available at: http://www.microsoft.com/interop/osp/default.mspx (accessed 4 September 2012).

Microsoft Corporation (2008f), “Steve Ballmer, Ray Ozzie, Bob Muglia, Brad Smith: Press Conference Call on Microsoft’s Strategic Changes in Technology and Business Practices to Expand Interoperability”, available at: http://www.microsoft.com/presspass/press/2008/feb08/02-21ConCallTranscript.mspx (accessed 4 September 2012).

Morris, Jr., J.B. (2011), “Injecting the Public Interest into Internet Standards”, in DeNardis, L. (Ed.), Opening Standards: The Global Politics of Interoperability, MIT Press, Cambridge, MA, pp. 3-12.

Murphree, M. and Breznitz, D. (2011), “Standardized Confusion? The Political Logic of China’s Technology Standards Policy”, in Industry Studies Association Conference in Pittsburgh, PA, 2011, pp. 1-35. 
Nee, V. (2003), “New Institutionalism, Economic and Sociological”, Working Paper, Center for the Study of Economy and Society, Cornell University, available at:

http://www.soc.cornell.edu/faculty/nee/pubs/newinstitutionalism.pdf (accessed 30th of July 2013).

NoOOXML (2008), “Microsoft's Wikipedia editor goes to the BRM to represent Australia”, available at: http://www.noooxml.org/forum/t-41947/microsoft-s-wikipedia-editor-goes-to-the-brm-to-representaustralia (accessed 4 September 2012).

North, D. C. (1994), “Economic performance through time”, The American Economic Review, Vol. 84 No. 3, pp.359-368.

OASIS (2008), “OASIS Open Document Format for Office Applications (OpenDocument) TC”, available at: http://www.oasis-open.org/committees/tc home.php?wg abbrev=office (accessed 4 September 2012).

OASIS ODF Adoption TC (2006), "Open by Design: The Advantages of the OpenDocument Format (ODF) ”, available at: http://opendocument.xml.org/open-design-advantages-opendocument-format-odf (accessed 4 September 2012).

ODF Alliance (2008), “Ecma’s Proposed Disposition of Comments on OOXML”, available at: httpL//www.openforumeurope.org/library/ODF/disposition-20of-20comments.pdf (accessed 4 August 2013).

Open Document Format Alliance (2006), “Open Document Format Alliance Response to the Burton Group’s Report”, available at: http://www.odfalliance.org/resources/BurtonGroupResponseFinal.odt (accessed 4 September 2012).

Orion, E. (2007), “ISO boards face OOXML deadline pressure”, available at: http://www.theinquirer.net/inquirer/news/1014706/iso-boards-face-ooxml-deadline-pressure (accessed 4 September 2012).

O'Kelly, P. and Creese, G. (2008), “What's Up, .DOC? ODF, OOXML, and the Revolutionary Implications of XML in Productivity Applications", Burton Group, available at: http://research.itpro.co.uk/whitepaper2387 (accessed 4 September 2012).

Pepoli, B. and Dormtzer, H. (2007), “Statement on ETRM v4.0 Public Review Comments”, Cover Pages, available at: http://xml.coverpages.org/ITD-ETRMv40-Statement.html (accessed 4 September 2012).

PHP Framework Interoperability Group (2013), “php-fig/fig-standards · GitHub”, available at: https://github.com/php-fig/fig-standards (accessed 30 August 2013).

Portugal-Perez, A., Reyes, J.-D. and Wilson, J.S. (2010), “Beyond the Information Technology Agreement: Harmonisation of Standards and Trade in Electronics”, The World Economy, Vol. 33 No. 12, pp.1870 1897.

Puolamäki, K. (2007), “Corrupt Countries were More Likely to Support the OOXML Document Format”, available at: http://www.effi.org/blog/kai-2007-09-05.en.html (accessed 4 September 2012).

Rens, A. (2011), “Open Document Standards for Government: The South African Experience”, in DeNardis, L. (Ed.), Opening Standards: The Global Politics of Interoperability, MIT Press, Cambridge, MA, pp. 63-74.

Sayer, P. (2008), “Changes to OOXML draft standard waved through”, InfoWorld, available at: http://www.infoworld.com/t/applications/changes-ooxml-draft-standard-waved-through-414 (accessed 1 September 2013).

Schestowitz, R. (2008), “The Latest OOXML/ODF FUD from the Philippines, Microsoft and Gates Go Batting in Europe”, Techrights, available at: http://boycottnovell.com/2008/01/23/ooxml-deceptivearticle/ (accessed 4 September 2012). 
Schmidt, V.A. (2008), “Discursive Institutionalism: The Explanatory Power of Ideas and Discourse”, Annual Review of Political Science, Vol. 11 No. 1, pp. 303-326.

Seabra, R. (2007), “Notes from Portugal on the July 16th Meeting on Ecma-376”, available at: http://www.groklaw.net/articlebasic.php?story=2007071812280798 (accessed 4 September 2012).

Shah, R., Kesan, J. and Kennis, A. (2007), "Lessons for open standard policies: A case study of the Massachusetts experience", in Proceedings of the 1st international conference on Theory and practice of electronic governance in Macao, 2007, pp.141-150.

Shankland, S. (1999), “Sun buying Microsoft Office competitor”, CNET, available at: http://news.cnet.com/2100-1001-230096.html (accessed 4 September 2012).

Silva, J. (2008), "Finally: the details about the final results of the BRM”, available at: http://homembit.com/2008/03/finally-the-details-about-the-final-results-of-the-brm.html (accessed 4 September 2012).

Siponen, M. and Willison, R. (2009), “Information security management standards: Problems and solutions”, Information \& Management, Vol. 46 No. 5, pp.267-270.

Sowa, J. (2004), “The Law of Standards”, available at: http://www.jfsowa.com/computer/standard.htm (accessed 4 September 2012).

Standards Australia (2011), “Membership Rules of Standards Australia Limited”, available at: http://www.standards.org.au/OurOrganisation/AboutUs/Documents/Membership\%20Rules\%20approve d\%2016\%20Nov\%202012.pdf (accessed 31 August 2013).

Thevenot, L. (2009), "Postscript to the Special Issue: Governing Life by Standards: A View from Engagements”, Social Studies of Science, Vol. 39 No. 5, pp. 793-813.

Timmermans, S. and Epstein, S. (2010), “A World of Standards but not a Standard World: Toward a Sociology of Standards and Standardization”, Annual Review of Sociology, Vol. 36 No. 1, pp 69-89.

Updegrove, A. (2008a), “ISO TMB Recommends Rejection of OOXML Appeals”, available at: http://www.consortiuminfo.org/standardsblog/article.php?story=20080709060030380 (accessed 4 September 2012).

Updegrove, A. (2008b), “ISO and IEC Reject OOXML Appeals”, available at: http://www.consortiuminfo.org/standardsblog/article.php?story=20080815093816875 (accessed 4 September 2012).

Updegrove, A. (2008c), “Microsoft Makes Major 'Openness’ Announcement on Eve of BRM (Updated) ”, available at:

http://www.consortiuminfo.org/standardsblog/article.php?story=20080221092839846\&query=Microso ft+Makes+Major (accessed 4 September 2012).

Updegrove, A. (2007), “OOXML End Game: Things Start to Become Interesting”, available at: http://www.consortiuminfo.org/standardsblog/article.php?story=20070718060228231\&query=OOXM L+End+Game (accessed 4 September 2012).

Vrancken, J., Kaart, M. and Soares, M. (2008), “Internet addressing standards: A case study in standards dynamics driven by bottom-up adoption”, in The Dynamics of Standards. Edward Elgar Publishing, pp. 68-81.

Van Dijk, T.A. (1993), "Principles of Critical Discourse Analysis”, Discourse \& Society, Vol. 4 No. 2, pp.249-283. 
Van Wegberg, M. (2004), "Standardization and Competing Consortia: The Trade-Off between Speed and Compatibility”, International Journal of IT Standards \& Standardization Research, Vol. 2 No. 2, pp.18-33.

Weir, R. (2008), “Punct Contrapunct”, available at: http://www.robweir.com/blog/2008/02/punctcontrapunct.html (accessed 4 September 2012).

Weir, R. (2007), “Sometimes I need to remind myself”, available at: http://www.robweir.com/blog/2007/04/sometimes-i-need-to-remind-myself.html (accessed 4 September 2012).

Weir, R. (2009), “Whither ODF?”, available at: http://www.robweir.com/blog/2009/02/whither-odf.html (accessed 4 September 2012).

Weiss, G.J. and Enck, J. (2006), “Microsoft Makes Strong Financial Commitment to Novell’s Linux”, Gartner, available at: http://www.gartner.com/DisplayDocument?doc_cd=144678 (accessed 4 September 2012).

Weiss, M. and Cargill, C. (1992), "Consortia in the standards development process", Journal of the American Society for Information Science, Vol. 43 No. 8, pp. 559-565.

Winterford, B. (2008), "Microsoft: IBM Masterminded OOXML Failure”, ZDNet, available at: http://news.zdnet.co.uk/software/0,1000000121,39292492,00.htm (accessed 4 September 2012). 